\title{
La publicidad en España como elemento de marketing: límites
}

\author{
Fernando RAmos FERNÁNDEZ \\ Universidad de Vigo \\ ferramos@uvigo.es \\ Teresa PIÑEIRO OTERO \\ Universidad de A Coruña \\ teresa.pineiro@udc.es \\ David CAldevilla Domínguez \\ Universidad Complutense de Madrid \\ davidcaldevilla@ccinf.ucm.es
}

Recibido: 24/07/2012

Aceptado: 22/10/2012

\begin{abstract}
Introducción
El nuevo Código Penal incluye el delito publicitario entre sus previsiones, al observar el creciente riesgo que genera la osadía creativa de algunos publicitarios, para quienes los límites de la, aceptada socialmente, exageración publicitaria, no se detienen ante lo engañoso, la creación de confusión o la buena fe de los consumidores. La autorregulación publicitaria, mediante la aplicación de códigos deontológicos es un paliativo para evitar el remedio judicial, al tiempo que denota que el engaño consciente o el incumplimiento de las reglas que regulan la publicidad o el lícito comercio es aceptada por algunos sin el menos escrúpulo. Escudándose en la libertad de expresión se introduce en el mercado mucha información contaminada. Si no se detecta a tiempo, los riesgos para el consumidor engañado son muchos, los mismos que para el comerciante leal.
\end{abstract}

Palabras clave: Autocontrol. Publicidad desleal y engañosa. Derechos de los consumidores. Creatividad publicitaria. Comercio lícito.

\section{Advertising in Spain as a marketing element: limits}

\begin{abstract}
The new Criminal Code offense advertising includes among its provisions, noting the growing risk generated by the creative audacity of some advertising, for those limits, socially accepted, hype, do not stop at what misleading, creating confusion or the good faith of consumers. Advertising self-regulation through the application of codes of ethics is a palliative to avoid judicial remedy, while denoting that conscious deception or breach of the rules governing advertising or lawful commerce is accepted by some without the least scruple. Hiding behind freedom of speech is introduced into the market much information contaminated. If not detected early, the risks to consumers are deceived many, the same as for the fair trader. Keywords: Unfair and deceptive advertising. Consumer rights. Advertising creativity. Lawful commerce.

\section{Referencia normalizada}

RAMOS FERNÁNDEZ, Fernando; PIÑEIRO OTERO, Teresa y CALDEVILLA DOMÍNGUEZ, David (2012): "La publicidad en España como elemento de marketing: límites". Estudios sobre el mensaje periodístico. Vol. 18, núm. especial noviembre, págs.: 741-751. Madrid, Servicio de Publicaciones de la Universidad Complutense.

Sumario: 1. La publicidad y sus efectos sobre los consumidores. 2. Libertad de expresión y creatividad publicitaria. 3. La autorregulación publicitaria en España. 4. El efecto de los anuncios sobre los consumidores. 5. Los estándares del estilo de vida que promueve la publicidad. 6. Las nuevas herramientas para la defensa de los consumidores. 7. La eficacia del Jurado de la Publicidad. 8. Conclusiones. 9. Referencias bibliográficas. 10. Legislación.
\end{abstract}




\section{La publicidad y sus efectos sobre los consumidores}

McLuhan (1996: 237) afirma que los anuncios no están hechos para ser consumidos conscientemente. Son concebidos como píldoras subliminales para el inconsciente con el fin de producir un trance hipnótico. Es cierto que la publicidad contribuye al bienestar del consumidor dándole información. La doctrina económica tradicional gusta de distinguir entre publicidad informativa y persuasiva, atribuyendo a la segunda alcance o efectos comerciales o mercantiles. En este sentido precisaron que un mismo bien, publicitado o no, es objetivamente una cosa distinta.

La publicidad es una vía de transmisión de parámetros de comportamientos sociales, vinculada a la cultura del consumo (Carrillo, 97: 11). De la Cuesta Rute (1985: 47), al afirmar que "los actos publicitarios, desde el punto de vista jurídico, se caracterizan por su finalidad mercantil más que por su estructura comunicativa", nos enseña que, al provocar efectos de orden patrimonial que el Derecho conoce, generan responsabilidades no sólo de orden civil y mercantil, sino también, y ahora, penales. Hoy ya no bastan las medidas administrativas, mercantiles o civiles.

La reflexión fundamental nos lleva a considerar que el objetivo original de la publicidad ha sido persuadir para consumir el producto anunciado. Martínez Rodrigo y Sánchez Martín (2011: 469) centran la discusión en el concepto de finalidad de la publicidad, aseverando que "en sus inicios, el discurso publicitario mostraba las características básicas del objeto, sus atributos propios y sus bondades. Sin embargo, esta narrativa ha ido evolucionando hasta la actualidad, en donde predomina un discurso centrado en la venta de emociones y experiencias. [...] No se vende el artículo de forma directa, sino que se apela a significados concretos, universalmente conocidos y, por tanto, fácilmente identificables, que son los deseados por el receptor. Estos elementos simbólicos en venta son emociones asociadas al consumo del producto". Este proceso desde lo demostrativo a la aspiración sirve de base a los publicistas para elaborar su mensaje, centrándolo en el pathos por encima del ethos y del logos.

Cuando se transmite un mensaje, el sujeto activo desarrolla una forma específica de libertad de expresión. El hecho de que lo haga con ánimo de lucro determina el contenido y la responsabilidad que del mismo se desprende. Tribunal Constitucional español, y el Supremo de los Estados Unidos, negó, en el primer caso, y matizó severamente en el segundo, que la libertad de expresión (tal y como la formula el artículo $20 \mathrm{CE}$ o la Primera Enmienda de la de los Estados Unidos) pudiera ser invocada indistintamente a la hora de emitir informaciones y opiniones, o reclamos publicitarios, cosa esencialmente distinta. Los norteamericanos dicen que cuando se redactó la Primera Enmienda, "no estaban precisamente pensando en los vendedores de pucheros".

La Ley 26/1984, de 19 de julio, General de la Defensa de los Consumidores, modificó la vieja concepción de que la publicidad trataba simplemente de una información inocua, que no exigía garantía de cumplimiento o responsabilidad como consecuencia de sus contenidos. Las normas de protección de los consumidores establecen que éstos pueden exigir el cumplimiento efectivo de las prestaciones o conte- 
nidos de los anuncios o reclamos publicitarios, aun cuando no figuren expresamente en el contrato celebrado (art. 8.1) ${ }^{1}$.

\section{Libertad de expresión y creatividad publicitaria}

El Tribunal Europeo de Derechos Humanos ha extendido, por igual, la protección del artículo $20 \mathrm{CE}$ a la información periodística y a la publicidad. Los publicitarios se aprovechan de este hecho; pero la doctrina insiste en preguntarse si el concepto de libertad de expresión, tal y como lo formula nuestra Constitución o la Primera Enmienda de la de los Estados Unidos, es aplicable, en toda su extensión a la creación publicitaria. Esta preocupación está motivada, en ocasiones, por el escándalo social (tan rentable, por otro lado, desde el propio punto de vista publicitario), provocado por algunas conocidas campañas. El Tribunal Constitucional entendió que la Constitución, en este sentido, no debía interpretarse en sentido amplio. En principio no apreciaron que la libertad de expresión del artículo 20 pudiera hacerse extensiva a la información persuasiva o comercial, precisamente por este carácter y finalidad económicos de la misma. Pero el Tribunal Europeo de Derechos Humanos impuso otro criterio, la libertad ante todo. La responsabilidad, después.

La directiva 84/450 CEE otorgó a los estados un amplio margen de maniobra para que, a través de las respectivas legislaciones nacionales, siempre en armonía con aquella directiva, se establecieran mecanismos judiciales y/o administrativos que permitan combatir eficazmente la competencia desleal tan vinculada al concepto mismo de publicidad engañosa. El Tratado de la Unión Europea (Tratado de Maastricht de 1992) introduce en el documento constitutivo de la Comunidad Europea, dentro del Título XI, la protección de los consumidores, en artículo 129 a., indicando que la Comunidad contribuirá a que se alcance un alto nivel de protección de los consumidores. ${ }^{2}$

\section{La autorregulación publicitaria en España}

Desantes (1973: 213) definía la deontología como el conjunto de las normas éticas objetivas para una colectividad profesional, independientemente del grado de positivización a que hayan llegado, bien sean normas de rango legal, estatutario de las organizaciones profesionales; normas convencionales, incorporadas o no a los convenios, o meros principios, aceptados comúnmente.

${ }^{1}$ Los productos deben incorporar de forma cierta y objetiva información veraz, eficaz y suficiente (art.13). Lo que diga un anuncio tiene que cumplirse. De ahí que los publicitarios huyan de decir cosas concretas, de las que se desprendan denotaciones determinadas. Se mueve en el terreno de lo simbólico, buscando connotaciones sublimes, pero que no dicen realmente nada. Suscitan o tratan de suscitar emociones.

2 a) Medidas de aproximación de las disposiciones legales, reglamentarias y administrativas de los Estados miembros que tengan por objeto el establecimiento y funcionamiento del mercado interior (art.100 a); b) Acciones concretas que apoyen y complementen la política de los Estados miembros a fin de proteger la salud, la seguridad y los intereses económicos de los consumidores, de garantizarles una información adecuada. Las acciones concretas no obstarán a que los Estados miembros adopten medidas de mayor protección. 
En España la Asociación para la Autorregulación de la Comunicación Comercial (Autocontrol) es una asociación sin ánimo de lucro compuesta por anunciantes, agencias, medios de comunicación y otras empresas de servicios a la comunicación comercial, que en conjunto representan más del $90 \%$ de la inversión publicitaria española, y por diversas asociaciones empresariales. Su objetivo es prevenir y resolver eventuales controversias publicitarias, estableciendo un marco ético donde se desenvuelva una comunicación comercial responsable y veraz.

Este proyecto colectivo, nacido el 13 de junio de 1995, ha logrado dotar al sector de un instrumento de resolución extrajudicial de controversias en materia publicitaria, así como de un sistema voluntario de consulta previa ("copy advice" e informes) que beneficia tanto a los consumidores como a la propia industria publicitaria. Autocontrol es miembro de la Alianza Europea para la Ética Publicitaria (EASA, European Advertising Standards Alliance), con sede en Bruselas, en cuyo seno se reúnen los sistemas de autorregulación publicitaria de los 15 Estados miembros de la Unión Europea y de otros países.

El Código de Conducta Publicitaria de Autocontrol fue probado en la Asamblea General Extraordinaria celebrada el 19 de diciembre de 1996. La última versión, con las modificaciones aprobadas por la Asamblea General Ordinaria, data del día 26 de abril de 2011. Estas normas deontológicas se aplican a toda actividad de comunicación publicitaria tendente a fomentar, de manera directa o indirecta y sean cuales fueren los medios empleados, la contratación de bienes o servicios, o el potenciamiento de marcas y nombres comerciales ${ }^{3}$.

${ }^{3}$ Códigos deontológicos y convenios en los que participa Autocontrol:

- Publicidad Cervezas: Convenio con Cerveceros de España (2003)

- Publicidad Bebidas Espirituosas: Convenio con FEBE (2003)

- Publicidad Televisiva: Convenio AUTOCONTROL - AEA - operadores de TV (junio 2002).

- Convenio SETSI (Ministerio Industria)-Autocontrol (2003)

- Publicidad Interactiva y Comercio Electrónico: Convenio AUTOCONTROL - AECE para cogestionar CONFIANZA ONLINE. (2002)

- Promoción de Medicamentos: Convenio con Farmaindustria (2002)

- Defensa de la Marca: Convenio con ANDEMA (2004)

- Publicidad de Alimentos y Bebidas dirigida a niños, Código PAOS: Convenio FIAB- Ministerio Sanidad-Autocontrol (2005)

- Publicidad de Videojuegos: Convenio con ADESE (2005)

- Publicidad de Tecnología Sanitaria: Convenio FENIN (2006)

- Autorregulación del Mercado de Investigación: Convenio con ANEIMO (2006)

- Publicidad de Productos de Nutrición Enteral: Convenio con Asociación Española de Fabricantes y Distribuidores de Productos de Nutrición Enteral

- (AENE) (2006)

- Convenio firmado con Red.es para la resolución de controversias en la asignación de dominios “.es" (2006)

- Publicidad sobre alimentos especiales, dietéticos, y plantas medicinales: Convenio con AFEPADI (2007)

- Publicidad de medicamentos dirigida al público: Convenio con la Asociación para el Autocuidado de la Salud (ANEFP) (2007) 
Constituido en octubre de 1995, el Jurado de Ética Publicitaria es un órgano especializado, e independiente, creado en el seno de la asociación, dedicado a la observación y seguimiento de las pautas deontológicas en el ámbito de la publicidad. Está compuesto por diez miembros, incluido su presidente. Todos son nombrados por la junta directiva. Cuatro componentes, entre ellos el presidente, son juristas de reconocida competencia, y el resto expertos en materias publicitarias. Su mandato es de tres años. Desde el inicio de su actividad ha conocido más de 2.500 casos. Ofrece un servicio de consulta previa, no vinculante, para que los anunciantes sometan a revisión sus anuncios antes de emitirlos.

El profesor De la Cuesta Rute (1985: 47 y ss.) sostiene que, desde el punto de vista jurídico, los anuncios deben ser evaluados por el efecto que causan en el patrimonio de los ciudadanos, al promover el tráfico mercantil, y no solamente por su belleza u originalidad. Los anuncios no son obras de arte, sino mecanismos de marketing y promoción de la venta, y cuando promueven la confusión y el quebranto económico puedan llegar a incurrir en supuestos de ilicitud penal. Es en la televisión donde hallamos más publicidad contaminada, que en el cómputo global de los anuncios controvertidos puede llegar a cuatro de cada diez reclamos cuyo contenido ha merecido el reproche de los consumidores, las administraciones o la competencia, puesto que no conviene olvidar que la publicidad engañosa es al mismo tiempo desleal, pues quebranta las reglas de juego del lícito comercio.

En 2011, Autocontrol recibió casi 18.000 consultas diversas sobre los anuncios a emitir, lo que refleja que los anunciantes y los publicitarios quieren curarse en salud ante de emitir anuncios que puedan contravenir la legislación protectora de los consumidores. La extensión de una postura crítica frente a las agresiones de la publicidad es una muestra de la madurez de los ciudadanos. ${ }^{4}$

\section{El efecto de los anuncios sobre los consumidores}

William Meyers, (1994: 24-31) ex publicista, experto en temas de publicidad, colaborador del New York Times, afirma que para conseguir que el público no deserte de su deber de consumir, la avenida de la Publicidad (se refiere a Madison Square, donde se encuentran las principales agencias de publicidad del mundo) creó una nueva técnica de marketing: la transformación de la imagen.

Dice Meyers que una campaña que ofrece a la una recompensa emocional aumenta su percepción con respecto a algo. Los escrúpulos morales quedan en segundo plano.

- Publicidad del vino: Convenio con la Federación Española del Vino (FEV) (2009)

- Publicidad Medioambiente: Acuerdo con el Ministerio de Medio Ambiente y Medio Rural y Marino, y empresas del sector energético y de automoción (2009)

- Publicidad de Juguetes: Convenio con la Asociación Española de Fabricantes de Juguetes (AEFJ) y el Instituto Nacional de Consumo (INC) (2010)

- Publicidad de Servicios de búsqueda de pareja y amistad: Convenio con eDarling, Meetic y Parship (2011)

${ }^{4}$ Después de la televisión, es ya Internet el ámbito donde la publicidad engañosa crece a ritmo exponencial. 
"La gente ya sabe que la publicidad exagera y cada uno se cree lo que quiera", se escudan cínicamente.

El profesor Lema Devesa (2007: 387) afirma al respecto: "La exageración encierra una alegación concreta y comprobable, ya que la frase que integra esta modalidad publicitaria posee un contenido determinado, cuya veracidad o falsedad puede fijarse de acuerdo con las pautas generales". Entiende que en toda exageración pueda hallarse un núcleo de verdad, pero no es menos cierto que también puede ser interpretada como "una alabanza de tono altisonante, concreta y comprobable que posee un núcleo verdadero y que no es tomada en serio por el público".

En los mensajes publicitarios de nuestros días se superponen diversas funciones. Es decir, que no solamente se nos anuncia un producto (y/o una marca), sino que se predican sus cualidades, su simbología cultural, las consecuencias que de su uso se desprende y hasta el rol social que asumimos cuando consumimos una determinada marca. (Sánchez Guzmán, 1976: 139).

Y si damos el salto cualitativo desde el producto hasta la marca, coincidimos con Dafonte (2011: 45) en que "el conocimiento de los consumidores y con el contexto sociocultural no figuran en ninguno de los otros modelos clásicos; sin embargo es obvio que en la creación de cualquier empresa, hoy en día, se tienen muy en cuenta las demandas -latentes o manifiestas- del mercado, para detectar las oportunidades de negocio, y también la influencia del contexto sociocultural en cuanto a valores y actitudes [...]aspectos que influirán en todas y cada una de las decisiones en torno a la identidad". Se trata, en resumen de ofrecer lo que se está dispuesto a admitir.

\section{Los estándares del estilo de vida que promueve la publicidad}

McBride (1980: 194) afirma que por centrarse fundamentalmente en la venta de bienes y servicios que la evalúan en términos monetarios, la publicidad tiende a promover unas actitudes y estilos de vida que exaltan la compra y el consumo de bienes en detrimento de los demás valores. Chomsky y Herman (2000: 11) opinan que la publicidad condiciona al medio, pues quiere atraerse para sí audiencias lucrativas que les proporcionen beneficios económicos y no audiencias que no posean fuerza económica para consumir 5 .

Si el lenguaje publicitario se encuentra instalado en el campo de la comunicación es por su capacidad para trasladar los significados a la sintonía de las afinidades, en un proceso intercambiable y continuo que va de la naturaleza de las cosas a la naturaleza de las gentes, con todos sus códigos de interpretación y de inducción

\footnotetext{
${ }^{5}$ La publicidad comercial dispone de recursos muy superiores a los de los individuos o los grupos que no están de acuerdo con una campaña de ventas; y esos recursos rebasan incluso a menudo los de los poderes públicos. La mayoría de los países imponen controles y garantías diversas, tales como códigos de conducta para los anunciantes, normas legislativas encaminadas a comprobar la veracidad de las afirmaciones y requisitos de acuerdo previo. Pero no siempre se cumplen. Desde la psicología de la comunicación, se afirma que la publicidad constituye un intento de influir sobre las personas con un fin determinado y sin coacción (Kagelmann y Wenninger, 1996: 34 y ss.). Se trata de una influencia intencionada. El principal objetivo publicitario es el aumento de las ventas (objetivo económico).
} 
"La publicidad se mueve especialmente cómoda dentro del universo de la metáfora. Estimula, desde su lenguaje natural el juego comparativo, las substancias adjetivas de las palabras más en su simbolismo que en su literalidad, entre lo enunciable y lo anunciable. El verbo es, en la publicidad radiada el eje substancial del mensaje radiofónico. Es el elemento que da coherencia a todo el mensaje. La publicidad radiofónica gusta de apoyarse en formas imperativas: «ven, mire, compre, haga, pruebe, tome»" (Ferrer, 1995: 43 y ss.).

\section{Las nuevas herramientas para la defensa de los consumidores}

En el caso de España, en cumplimiento de los objetivos fijados en las directivas europeas, se han ido introduciendo progresivas medidas para la defensa de los consumidores, pero al mismo tiempo para acabar con las frecuentes prácticas de publicidad desleal que tanto perjudican al comerciante y al publicitario, honrados. En este sentido, la Ley 29/2009, de 30 de diciembre, por la que se modifica el régimen legal de la competencia desleal y de la publicidad para la mejora de la protección de los consumidores y usuarios está siendo un instrumento adecuadamente eficaz.

Especialmente relevante es el concepto de «consumidor medio», acuñado por la jurisprudencia del Tribunal de Justicia de las Comunidades Europeas como la reacción típica del consumidor normalmente informado, razonablemente atento y perspicaz, teniendo en cuenta los factores sociales, culturales y lingüísticos. En consecuencia, no es un término que la ley haya de definir, sino que han de ser los tribunales los que van a efectuar su concreción en cada caso concreto.

La relevancia de la publicidad en el proceso de toma de decisiones de los ciudadanos es cada vez mayor. Por ello, cobra especial sentido la pervivencia del concepto de publicidad ilícita en el ámbito de la Ley General de Publicidad garantizando las acciones y remedios que posibilitan su represión, especialmente frente a la publicidad que atente contra la dignidad de la persona o vulnere los derechos y valores reconocidos en la Constitución, significativamente en lo que se refiere a la infancia, la juventud y la mujer. ${ }^{6}$

\section{La eficacia del Jurado de la Publicidad}

Las decisiones del Jurado de Autocontrol son de obligado cumplimiento para los socios y voluntaria para el resto de casos sobre los que recaigan sus resoluciones, pero

${ }^{6}$ El problema surge en ocasiones por el concurso entre la Ley General de Publicidad y la Ley de Competencia Desleal, que hace necesario, y así lo recoge la jurisprudencia, la introducción de mecanismos de coordinación. Se modifica la Ley General de Publicidad, para disponer de un mismo cuerpo de acciones y remedios contra todas las prácticas comerciales que perjudiquen los intereses económicos de los consumidores, sin renunciar a la regulación específica de la publicidad y sin menoscabo de la legitimación especial que en la Ley General de Publicidad se establece frente a la publicidad ilícita por utilizar de forma vejatoria o discriminatoria la imagen de la mujer. 
se supone que siempre tendrán repercusión social. No obstante, los socios, sean medios, anunciantes o agencias se comprometen a acatar las decisiones del Jurado ${ }^{7}$.

La propia memoria anual de "Autocontrol", correspondiente al año 2011, sobre esta controversia, señala:

"Pese a la voluntariedad del sistema, que sólo puede vincular estatutariamente a las entidades asociadas, es innegable la fuerza moral de la que gozan los pronunciamientos del Jurado de la Publicidad de Autocontrol en todo el sector, adheridos y no adheridos al sistema. La autoridad técnica y la imparcialidad demostrada por sus resoluciones han generado una alta credibilidad y confianza, tanto entre la industria publicitaria, como ante la Administración y la Sociedad en general. Buena muestra de ello es que, hasta la fecha, en menos de un 5\% del total de casos resueltos por el Jurado de la Publicidad, la empresa reclamada no ha cumplido la resolución dictada al efecto por el Jurado. En algunos de esos casos, cuando, tras haber sometido el asunto al Jurado de la $\mathrm{Pu}$ blicidad, las partes han acudido posteriormente a los Tribunales de Justicia, los pronunciamientos judiciales, hasta la fecha, han coincidido sustancialmente con el contenido de las resoluciones del Jurado previamente dictadas (excepto en un solo caso)". (Autocontrol, 2011)

Con respecto al ejercicio de 2011, los tres motivos principales de las reclamaciones presentadas por los consumidores, otras empresas o entidades mercantiles o la propia Administración que incluso usa esta vía fueron: la publicidad engañosa sin más (92 casos), la infracción del principio de legalidad en la publicidad de alimentos (cosa gravísima, 41 casos) o la infracción de códigos deontológicos sectoriales (43 casos; es decir, publicidad de productos milagro, publicidad de horario restringido, protección de la infancia, etc.). Otros casos notables son aquellos en que los anuncios denigran a la competencia o explotan el miedo.

Sobre un total de 148 casos, en 39; es decir, el 26 por ciento, el anunciante se avino con el reclamante a modificar o retirar el anuncio; pero el estimó totalmente las razo-

\footnotetext{
${ }^{7}$ Desde su creación, el Jurado de la Publicidad de Autocontrol ha resuelto más de 2.500 casos, en un tiempo medio de 14 días en primera instancia; en torno un 30\% se resolvieron por "mediación" o "aceptación" de la reclamación por el anunciante en un plazo medio de 5 días, con el consiguiente cese de la publicidad. Concretamente en 2011 se tramitaron 146 casos. La mayor parte de las reclamaciones presentadas ante Autocontrol procedían de consumidores u otras organizaciones ciudadanas (en torno al 65\%), siendo las presentadas por empresas o asociaciones empresariales el 31,5\% aproximadamente. La Administración también utiliza esta vía extrajudicial en muchas ocasiones; el 1,4\% de los casos tramitados en 2011 eran consecuencia de requerimientos de diferentes organismos de la Administración. Desde hace unos años el número de reclamaciones recibidas anualmente se ha estabilizado, gracias a la labor preventiva desarrollada por la Asociación, con un aumento considerable del uso de los servicios de consulta previa. Autocontrol cuenta con más de 428 miembros directos y 4.000 indirectos en estos momentos, lo que prácticamente representa la totalidad de los actores que intervienen en la publicidad en España.
} 
nes de 40 reclamaciones; es decir, el 27 por ciento, parcialmente en 23 casos, esto es casi el 16 por ciento y desestimó totalmente 36 reclamaciones; es decir, el 24 por ciento. Nada nuevo bajo el sol al analizar la causa de las resoluciones de Jurado de la Publicidad. La publicidad engañosa sigue siendo la causa más repetida de reclamaciones y decisiones del jurado, con una peligrosa evidencia de las infracciones que se producen en torno a la publicidad de productos alimentarios o de los casos de publicidad sujeta a regulaciones específicas, de carácter sectorial, que asimismo se vulneran.

Lo que está teniendo gran éxito es el servicio de Consulta Previa (Copy advice ${ }^{\circledR}$ ) que fue puesto en marcha por la industria publicitaria, a través de Autocontrol, como complemento del sistema de control post-emisión del anuncio y con el objetivo de reducir el riesgo de incumplimiento de las normas que regulan la publicidad. Se trata de un servicio de asesoramiento no vinculante sobre la corrección legal y ética de un proyecto de campaña o anuncio, antes de su difusión al público. Tal es el grado de aceptación de este servicio que, actualmente, es más solicitado que las propias intervenciones del Jurado, con más 62.700 consultas previas atendidas desde su puesta en marcha ${ }^{8}$.

Resulta especialmente llamativo, en torno a lo pertinaz del engaño, según los propios datos de Autocontrol, que entre los motivos que, tras la consulta previa, aconsejaron la modificación de determinados anuncios, casi medio millar se debiera a publicidad engañosa (a juicio del propio Jurado de la Publicidad); que hubiera caso mil anuncios, no dirigidos a menores con limitaciones horarias o de medio; además de otros 323 casos de publicidad engañosa dirigida a menores o anuncios perniciosos para los menores y sus relaciones familiares hasta 62 .

En el recorrido histórico desde que existe Autocontrol, los anuncios emitidos en televisión representan el mayor volumen de contaminación engañosa, seguida por la prensa y por un preocupante crecimiento de los casos registrados en Internet, donde cada vez se engaña más. No obstante son significativos los datos del engaño e marketing directo, publicidad exterior y etiquetado

\section{Conclusiones}

La proliferación de Códigos de Conducta Ética, abundantísimos en la publicidad parece más una estrategia de marketing e imagen que un sincero deseo de que la publicidad sea honesta y leal. El engaño y el incumplimiento de las normas que la afectan siguen siendo una herramienta de marketing, especialmente odiosa cuando se vulnera la buena fe de los consumidores.

Aunque la organización Autocontrol presume de su eficacia, no todos creen en la sinceridad de sus objetivos, sino más bien que es un recurso para tener buena prensa y evitar el remedio judicial.

${ }^{8}$ El Jurado de la Publicidad de Autocontrol también se encarga de la resolución extrajudicial de controversias sobre publicidad interactiva de CONFIANZA ONLINE. Este organismo nació a finales de 2002 por acuerdo de Autocontrol y Adigital (Asociación Española de la Economía Digital), antes AECEM. Su objetivo principal es aumentar la confianza de los consumidores en los nuevos medios interactivos. Actualmente, alrededor de 1.800 webs de empresas ya están adheridas. 
La justificación de que la exageración publicitaria está socialmente aceptada y que los públicos no se creen los anuncios ha sido corregida por la Unión Europea, en el sentido de que los reclamos deben ser interpretados como lo haría "El ciudadano medio"; es decir, el hombre de la calle. Si la publicidad no se corrige, el Estado se ha armado con una serie de medidas que pueden imponer el cumplimiento efectivo de las afirmaciones de los reclamos. De ahí que los publicitarios huyan de decir cosas concretas, de las que se desprendan denotaciones determinadas. Se mueve en el terreno de lo simbólico, buscando connotaciones sublimes, pero que no dicen realmente nada. Suscitan o tratan de suscitar emociones.

\section{Referencias bibliográficas.}

AUTOCONTROL (Asociación para la Autorregulación de la Comunicación Comercial) (2011): "Trabajamos por una publicidad responsable. Memoria y balance de actividad 2011". Madrid, ediciones de la Asociación para la Autorregulación de la Comunicación Comercial.

CARRILlO, Marc, (1997): Prólogo a BABÓ i BALBÉ. María Josep (1997): A publicidade ilícita e a defensa dos consumidores. Santiago de Compostela, Lea.

CHOMSKY, Noam y EDWARD S. Herman (2000): Los guardianes de la libertad. Barcelona, Planeta.

DAFONTE GÓMEZ, Alberto (2011): "Evolución de los rasgos culturales del formato televisivo Operación triunfo en España desde la perspectiva de la identidad de marca (2001-2011). Revista de Comunicación de la SEECI, $\mathrm{n}^{\circ} 25$ de julio. Disponible en: www.seeci.net/seeci/Numeros/Numero\%2025/Alberto.pdf. Consultado el 12 de julio de 2012.

DE LA CUESTA RUTE, José María (1985): Lecciones de Derecho de la Publicidad, Madrid. Madrid, Ediciones de la Universidad Complutense.

DESANTES GUANTER, José María (1973): El autocontrol de la actividad informativa. Madrid, Edicusa.

FERRER, Eulalio (1995): El lenguaje de la publicidad. México, Fondo de Cultura Económica.

KAGELMANN, H. Jürgen y WENNINGER, Gerd (1996): Psicología de los medios de comunicación. Barcelona, Herder.

LEMA DEVESA, Carlos (2007): Problemas jurídicos de la publicidad. Madrid, Marcial Pons.

MARTÍNEZ RODRIGO, Estrella y SÁNCHEZ MARTÍN, Lourdes (2012): "Publicidad en Internet: nuevas vinculaciones en las redes sociales". Revista de Comunicación Vivat Academia, $\mathrm{n}^{\circ}$ especial de febrero. Disponible en: www.ucm.es/info/vivataca/numeros/n117E/PDFs/Varios13.pdf. Consultado el 15 de julio de 2012. 
McBRIDE, Sean et al. (1980): Un solo mundo, voces múltiples. Informe sobre la Comunicación e Información en nuestro tiempo. México, Fondo de Cultura Económica.

McLUHAN, Marshall (1996): Comprender los medios de comunicación. Las extensiones del ser humano. Barcelona, Paidós Comunicación.

SÁNCHEZ GUZMÁN, José Ramón (1976): Breve historia de la publicidad. Madrid. Ediciones Pirámide.

\section{Legislación}

Ley 29/2009, de 30 de diciembre, modifica el régimen legal de la competencia desleal y de la publicidad para la mejora de la protección de los consumidores y usuarios.

Ley de Defensa de Consumidores y Usuarios es el Real Decreto Legislativo 1/2007, aprobado el 16 de noviembre de 2007 y publicado en el Boletín Oficial del Estado el 30 de noviembre.

Ley 43/2007, de 13 de diciembre, de protección de los consumidores en la contratación de bienes con oferta de restitución del precio.

Ley 23/2003, de 10 de julio, de Garantías en la Venta de Bienes de Consumo.

Ley 7/1998, de 13 de abril, sobre condiciones generales de la contratación.

Ley 34/1988, de 11 de noviembre, General de Publicidad

\section{Fernando RAMOS FERNÁNDEZ}

Universidad de Vigo

ferramos@uvigo.es

\section{Teresa PIÑEIRO OTERO}

Universidad de A Coruña

teresa.pineiro@udc.es

\section{David CALDEVILLA DOMÍNGUEZ}

Universidad Complutense de Madrid

davidcaldevilla@ccinf.ucm.es 